\title{
Space and Infrastructure Functionality in Yaounde Markets
}

\author{
Humphrey Ngala Ndi ${ }^{1} \&$ Emmanuel Ebai Enow Oben ${ }^{1}$ \\ ${ }^{1}$ Faculty of Social and Management Sciences, Department of Geography, University of Buea, Buea, Cameroon \\ Correspondence: Humphrey Ngala Ndi, Faculty of Social and Management Sciences, Department of Geography, \\ University of Buea, Buea, Cameroon. Tel: 237-77-88-5649. E-mail: hngalan117@gmail.com
}

Received: March 8, 2014 Accepted: April 1, 2014 Online Published: May 3, 2014

doi:10.5539/jgg.v6n2p93 URL: http://dx.doi.org/10.5539/jgg.v6n2p93

\begin{abstract}
Market infrastructure plays an undeniable role in the spatial configuration of cities and is central to their efficient functioning. This paper examines the implication of the nature of the social and economic infrastructure in the efficient functioning of market spaces in Yaounde. Over 180 traders in $72.2 \%$ of main markets in Yaounde were sampled through a stratified random sampling technique and authorities of the City Council and Sub-Divisional Councils, Market Directors, Market Presidents, and fire brigade workers were equally interviewed through a purposive sampling technique. Findings indicate that an increase in the population of traders is putting a strain on the ability of the local council to provide adequate marketing infrastructure. The absence of adequate market infrastructure has implications on health, sanitation, environment as well as the aesthetic value of markets. The non-site marketability of certain markets has resulted in underutilization. This study suggest a long term commitment by the Yaounde City Council authorities to provide adequate and adapted infrastructure in markets, stronger private sector involvement in market development and the introduction of community self-help programmes and the initiative of private 'traditional' market establishments so as to ensure efficient market development.
\end{abstract}

Keywords: market infrastructure, health and sanitation, functionality, operational inefficiency

\section{Introduction}

Urban infrastructures for communications, trade and other services are central to the urban landscape. They are often provided either by governments, councils or mutual assistance organisations (Adekunle et al., 2011; Jahangeer et al., 2012). Markets are one of these infrastructures. Though generally obscure, market architecture plays an undeniable role in the functioning of cities (Gantner, 2009). Gantner (2009) also observed that the transformation of Western economies from the traditional stage to post industrialisation and now to the contemporary and globalised stage was marked by a transition from the 'bazaar' (traditional) market to a firm-like distribution of stores and shops. This transformation was most obvious in cities of international importance and tourist destinations like Paris, Venice and New York. The retail landscape in Africa in general, and Cameroon and Yaounde in particular tends to be a mixture of the 'bazaar' on the one hand, and more structured shops and stores.

Tracy-White (1995), holds the view that the efficient operation of retail markets is influenced by its environment (market premises, accessibility, capacity, social infrastructure) and how that environment is managed. The study of the Nkwo-Ozuluogu market in Oraifite, Anambra State, and that of Oje and Oja'ba in Ibadan all in Nigeria, reveal that poor infrastructural development and planning is an impediment to their efficient functioning (Uzuegbunam, 2012; Adekunle, 2012). This also holds true for markets in Yaounde.

Although efforts are made to provide economic and social infrastructure in Yaounde's markets, they seem not to be keeping pace with the growth of the trading population because they are either absent, broken down or poorly planned given that markets in this city have an unplanned origin. They have evolved from local rather than government initiatives. Thus, infrastructural needs follow the market, and not markets following infrastructure as the case should be. In an effort to seek redress, partnerships have been encouraged between governments and businessmen on the build-operate-transfer principle. Despite this, economic and social infrastructure adapted to the needs of most traders is still lacking because the available stores are either very expensive and above the reach of the ordinary trader, or are non marketable. The cases in point are those of the Mvog Betsi market site and upper level shops in the Mokolo and the Central markets whose non-marketability has severely undermined their utilization. Given the importance of site marketability and adequate infrastructure to the efficient 
functioning of markets, this paper examines the implications of poor planning and inadequate social and economic infrastructure in the functioning of markets in the city of Yaounde.

\subsection{Study Area}

Yaounde, the capital of Cameroon is located between latitudes $3^{\circ} 47^{\prime}$ and $3^{\circ} 56^{\prime}$ north of the Equator and longitudes $11^{\circ} 10^{\prime}$ and $11^{\circ} 45^{\prime}$ east of the Greenwich Meridian. Figure 1 shows Yaounde in Cameroon, and in the Centre Region of Cameroon.

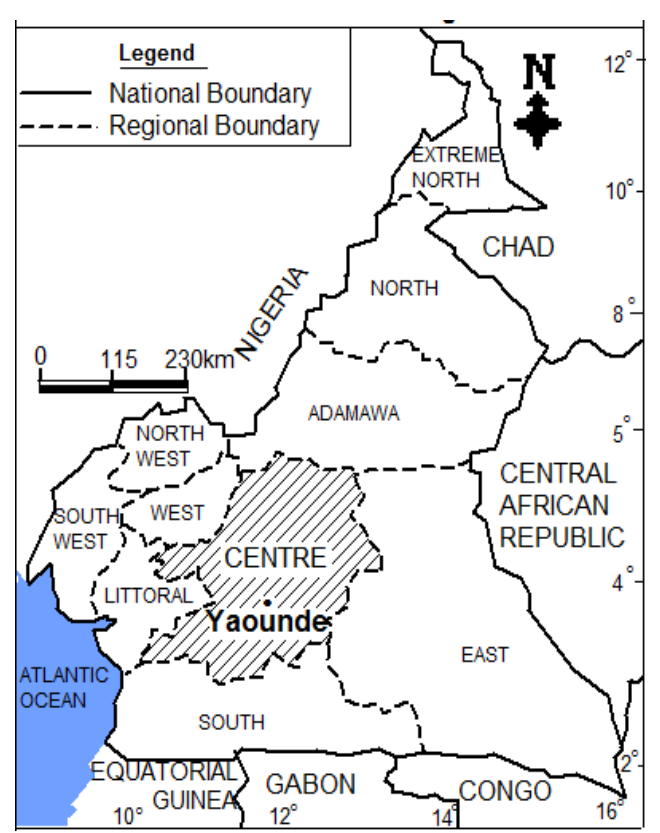

Figure 1(a). Yaounde in Cameroon

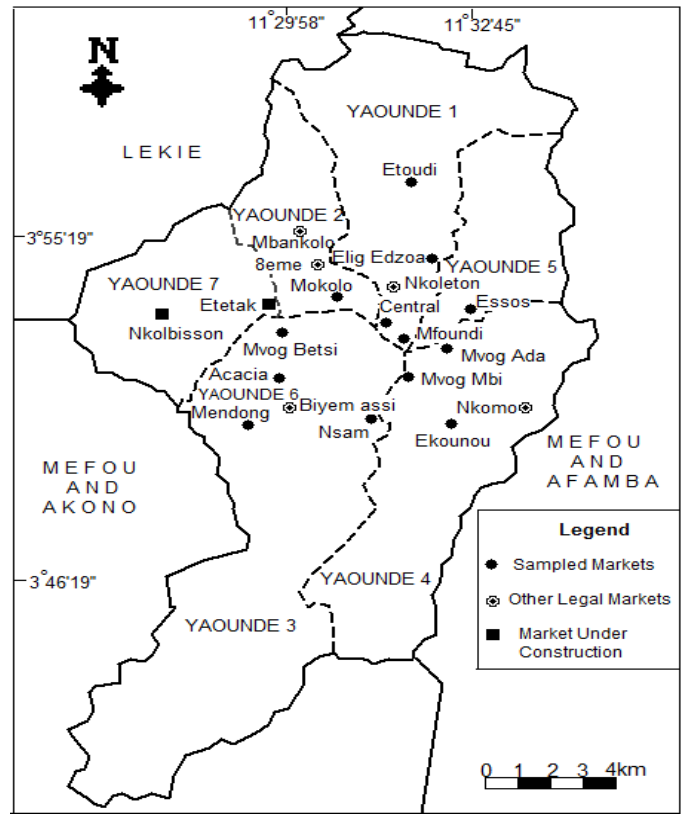

Figure 1(b). Distribution of markets in the SubDivisions of Yaounde

Figure 1. Location of the Yaounde Metropolis in the Centre Region of Cameroon

The Yaounde municipality is governed by the City Council instituted in 2004 within the framework of administrative decentralisation in the country. Among others, the missions of this local administration include the provisioning of communal equipment and infrastructure, creation of markets, organisation of trade fairs and the maintenance of hygiene and sanitation. Over time, the fulfilment of these missions has become daunting mainly because of inadequate and non-proactive policies aggravated by the rapid growth of the city's population. The population of Yaounde grew from 318,700 inhabitants in 1976 to 649,000 in 1987; 1,237,500 in 2000 and stands at about 2 million inhabitants presently (1976, 1987 and 2005 National Population and Housing Censuses). This population has been projected to reach 2.8 million by 2020 (PDU, 2008). Like population, the surface area of Yaounde increased from $240.98 \mathrm{~km}^{2}$ in 1980 to $287.98 \mathrm{~km}^{2}$ in 2001, representing a percentage growth of $20 \%$, and giving a population density of 153 inhabitants/ha (PDU, 2008). In a study on employment and the informal sector, (EESI-2005) cited in the PDU (2008), the service industry including commerce was shown to be employing over $78.70 \%$ of the active population of the city while the secondary and primary sectors employed $19.00 \%$ and $2.20 \%$ respectively. Commerce therefore constitutes a critical livelihood of more than three quarters of Yaounde dwellers.

\section{Research Methods}

A purposive sample of markets was done. That resulted in at least one market being chosen from each of the seven Sub-Divisions of the Yaounde municipality, except for Yaounde VII that does not have an official market. To appraise the level of the provision of socioeconomic amenities in Yaounde markets, a total of 180 questionnaires were administered to traders in the sampled markets. The questionnaire largely respected traders' specialization such as perishables, clothes and textiles, cosmetics, shoes and bags, electronics, household utensils and other hardware, stationery, livestock, layette, tailors and jewelleries. Furthermore, municipal authorities, market directors, presidents, and fire brigade workers were interviewed. Field observations and measurements of 
the dimension of market stalls were also carried out. Secondary sources were equally an important source of data. Data was mostly empirical and qualitative.

\section{Results and Analysis}

\subsection{Nature of Economic Infrastructure}

Naturally, the older and centrally located markets are better equipped than the newer ones mostly lying in the peripheries. The older and most important ones by virtue of their customer catchment areas, size, centrality, and the variety of goods sold are the Central, Mokolo and Mfoundi markets. Some newer and peripheral markets like Mvog Betsi and Acacia have been developed and equipped with some economic and social infrastructure. The Etoudi, Acacia and Mendong markets are presently under redevelopment. Generally, only about $30 \%$ of the markets studied have permanent structures designed for trade. Makeshift stalls abound and are very favourably predisposed to fires than those built with bricks and cement blocks.

The recent rehabilitation of the Mokolo market has witnessed the introduction of uniformly designed stalls that conform to the goods the traders sell. Figure 2(a) shows stalls used for the sale of groundnuts. They have an area of $1 \mathrm{~m}^{2}$ and a height of $65 \mathrm{~cm}$. This design prevents groundnuts from spilling to contiguous areas and guarantees maximum security by virtue of the fact that traders can seal the boxes with a padlock. Stalls constructed for perishables measure $1 \mathrm{~m}^{2}$, the authorised size, and a height of $70 \mathrm{~cm}$ (Figure 2b). However, some stalls are less than $1 \mathrm{~m}^{2}$ to the displeasure of most traders. A desk-like design which measures $1.1 \mathrm{~m}^{2}$ made for shoe menders and a stand which measures $70 \mathrm{~cm}^{2}$ for those selling shoes are shown in Figure 2(c) and 2(d) respectively. It is worthy of note that these structures are unique to the Mokolo market. This has helped to create a uniform landscape and improved on the aesthetics and functional efficiency of this market.
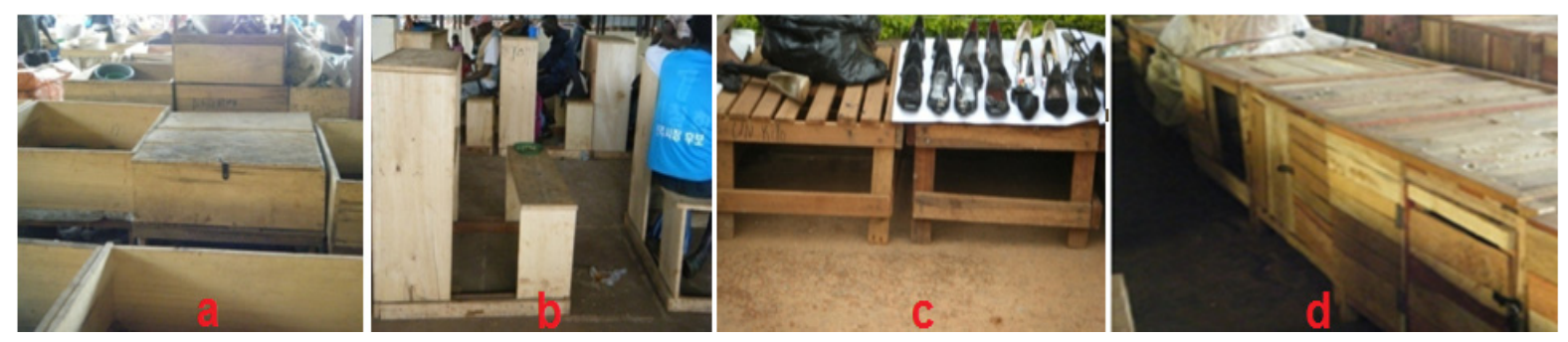

Figure 2. Stalls adapted to traders needs

\subsection{Infrastructural Carrying Capacity}

In an ideal situation, traders are supposed to sell in a well sheltered shop or a stall in order to avert adverse health risks resulting from environmental conditions. The situation in Yaounde is a mix of people trading in open spaces generally on, or adjacent to high streets on which many potential buyers converge in the typical bazaar fashion (3a); and those who sell in well-designed sheds and shops. Furthermore, other traders sell in any available crowded space irrespective of its hygienic conditions as Figure 3(b) depicts.
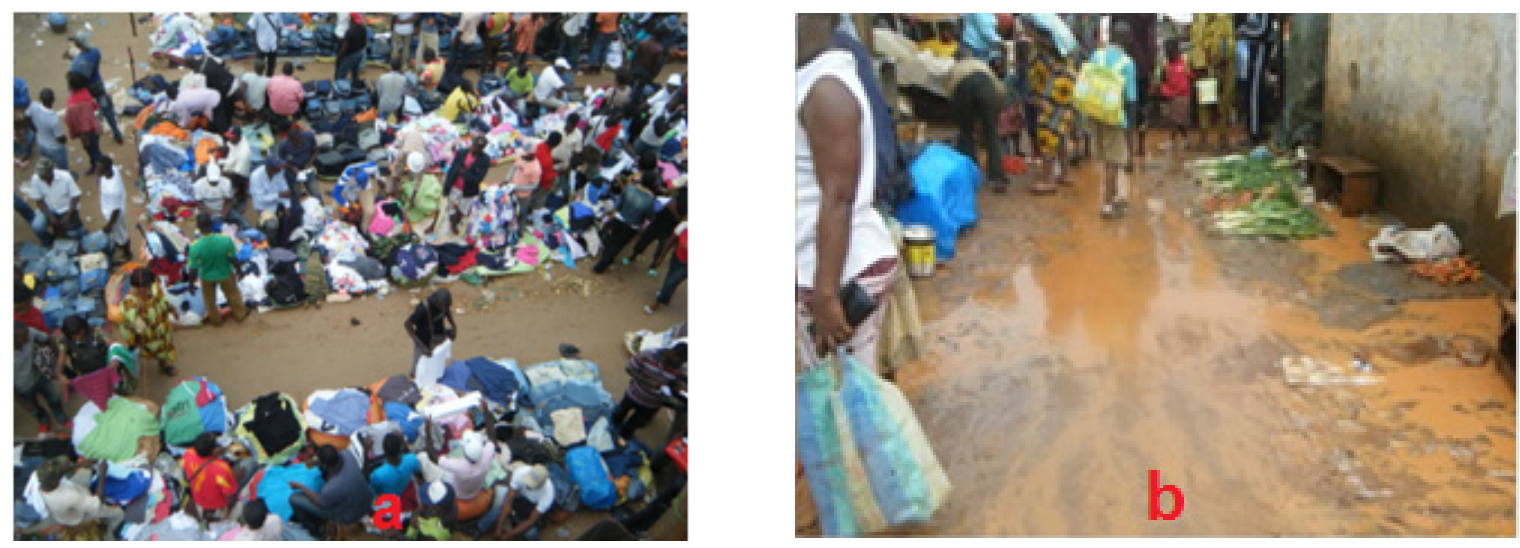

Figure 3. Open space trade in the Mokolo market vicinity 
As a result of inadequate infrastructure, non-marketability of sites, and ill-adapted markets, traders have improvised trading spaces such as selling under umbrellas and locally designed canopies. This has created unsightly and inefficient market landscapes, putting the health of traders at risk especially during the dry season, as they are highly exposed to heat stresses. Furthermore, it makes commerce an inconvenient activity as traders have to pack or cover their commodities with tarpaulin when rain falls. They also have to pack up their merchandise for lockup every evening, and unpack for display every morning, making trade in these markets a laborious activity.

The non involvement of all categories of traders in market space design has greatly contributed to their dysfunction. In the Mvog Ada market, for example, the builder stuffed the market with shops to the detriment of stands for petty traders. Consequently, the petty traders now occupy part of the internal road system and sidewalks, resulting in a hike in congestion and reduced accessibility to stalls and stands. In the Central market, the discordance between the size of shops constructed in 1953 and the throughput of traders has led to encroachments on aisles. This is common with traders who deal in bulky and awkward articles some of which outsize the $2.5 \mathrm{~m}^{2}$ stall area typical of this market. Consequently, they have occupied an average of $1 \mathrm{~m}$ out of the $2 \mathrm{~m}$ aisle width. Furthermore, because of the small sizes of shops, traders are forced to sit outside further encroaching on the aisles. In some situations, about five customers can crowd the aisle in front of a shop, waiting to buy. This has caused a lot of congestion as clients, truck pushers, hawkers struggle to move through the $1 \mathrm{~m}$ aisles.

The rehabilitation of the Acacia market was supposed to be carried out piecemeal so as not to significantly disrupt trading activities. As such, the developed sections needed to be occupied before further demolition and redevelopment. This was not the case, as demolition was done without proper relocation. Consequently, vendors occupied illegal sales spaces, while shop owners who dealt with relatively huge quantities of goods had no option than to retire home until the new shops were completed. While the carrying capacity of the Mokolo market has been augmented technically, in practice, the needs of small informal traders have not been met because the newly constructed shops are too expensive for them. It is perceived that about $80 \%$ of those who have bought and occupy newly constructed shops especially in the Mokolo market are the wealthy. Thus, access to adequate trading infrastructure by petty traders is problematic.

\subsection{Site Marketability}

A site is said to be marketable when it generates net profit above investment. The Mvog Betsi market has proven to be less profitable for trade in non-perishable commodities which occupy about $5 \%$ of the market. Out of 500 stalls, 360 have been rented out, but are permanently closed because of site non-marketability (Figure 4a). This gives a stall occupancy rate of $28 \%$ in the market. According to the Market Director, the shops were projected to generate the sum of about 3 million FCFA a month. However, only a meagre 500.000 FCFA is generated.

The operational inefficiency of this market has been partly blamed on its retail design. According to traders, an inversion of investment style in which shops dominate the down throw of the market, while perishables occupy the upper throw, so as to expose clients to non-perishables upon ascension to the perishable sector would improve on the marketability of this site. Other factors that contribute to the non-marketability of the site are: poor accessibility and the influence of the nearby bigger and more attractive Mokolo market.

The low occupancy of the upper level stalls in the markets in Yaounde can be blamed on the absence of segmentation. The more storeys you climb, the weaker the level of stall occupancy. This is true in the Central market which has five storeys. The fourth and fifth storeys are underutilised as Figure 4(b) shows. It was noticed that 130 stalls in the Central market are vacant because trade is unprofitable in these areas. The low upper level occupancy is also characteristic of the Mokolo market, in which 59\% of upper level stalls are not effectively occupied. The unprofitable nature of trade in storey-buildings is compounded by the fact that goods sold at the upper levels can easily be bought from the lower floors. This brings to fore the importance of segmentation in increasing the chances of all traders having exposure to potential customers. 

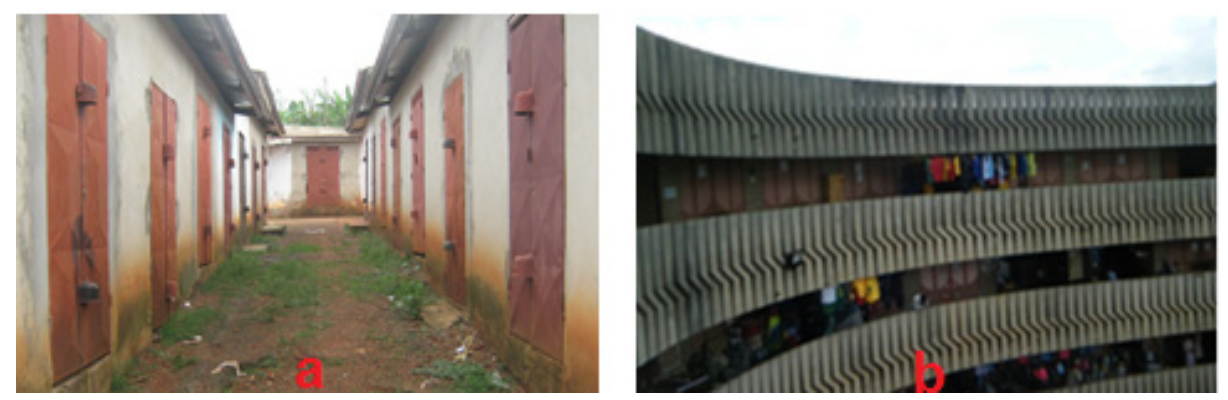

Figure 4(a). Vacant shops in the Mvog Betsi market, (b) Low occupancy in the Central market. NB: Pictures were taken on a Saturday when the customer density is often highest. Notice the quasi absence of traders on the $5^{\text {th }}$ floor of the Central market

\subsection{Social Infrastructure}

\subsubsection{Toilet Facilities}

The planning of toilet facilities is a major determinant of the degree of hygiene and sanitation in market environments. As indicated earlier, only one toilet block with four compartments has been constructed in the Essos market. This is inadequate when compared to the population of vendors, estimated at 2,500 and 3,000 during the holiday periods. Consequently, the toilet compartment to trader ratio is 1:625 during school periods and 1:750 during the holidays. If clients are included, the ratio will be much higher. As a result, people line up to use the toilet, thus, wasting time and losing potential customers as their goods lie idle. The maintenance of these facilities does not often keep pace with their use. Many are filthy, and unhygienic from poor use. Illegal toilets have therefore emerged. A total of three illegal toilets were identified around the Essos market, a situation common in many other markets. This has considerable health effects as flies could carry pathogenic substances to restaurants and other eating points in the markets. Obnoxious smells are also another consequence of the proliferation of illegal toilets.

The poor construction of one of the toilets in the Acacia market has sacrificed the convenience of trading around that section of the market. The septic tank was not deep enough to be able to adequately sustain sewage and once emptied, it takes an average of two weeks to get full again. The private owner only empties the tank after an average of two months from when it gets full. Thus, traders are forced to endure the smell for about 62 days. It is also worthy of note that this is the same situation with the Sociéte Immobilière du Cameroon (SIC) sewage system located in this market, which often flows to contiguous areas when it is blocked. In markets of the Yaounde municipality, $46 \%$ of traders are satisfied with the functioning of toilets while $54 \%$ are dissatisfied, from questionnaire analysis.

\subsubsection{Waste Disposal Facilities}

Efficient waste management in urban areas is a very huge challenge to city authorities. The main vessels for the evacuation of waste from the market to bins are wheel barrows and trucks. Considering the height of these bins, it is practically impossible for trucks and wheel barrows to be raised in order to dump waste into them. As a result, they dispose the waste on the ground, despite the availability of space in the bins resulting in nasty and unsightly scenes infested with flies and scavangers. The poor location of waste bins in the market especially that of Mokolo has led to the proliferation of illegal dump sites and the late evacuation of waste in markets creates habitat for rats and arthropods that spread typhus, salmonella, leptospirosis and other diseases as observed by Adewole (2009).

\subsubsection{Absence of Slaughter House}

The Mvog Ada market specialised in livestock does not have a modern slaughter house. As a result, pigs and chicken are slaughtered, deplumed in ill adapted and nasty milieus in which the slaughtered animals are susceptible to contamination. At times, waste is often disposed of in a tributary of the Mfoundi River that flows behind this market. The disinfectants applied in this area are often carried in runoff to the river. This has led to pollution and eutrophication.

\subsubsection{Nature of Aisles}

It was observed that $31 \%$ of markets studied have paved aisles (Mfoundi, Mokolo, Mvog Betsi and the Central market). As a result, shopping in them is relatively more convenient during the rainy season. On the other hand, 
$69 \%$ of markets are characterised by unpaved aisles which are very muddy during the rainy season as illustrated in Figure 5(a). This affects the suitability of trade coupled with the fact that about $95 \%$ of petty traders expose their articles on the ground, predisposing them to contamination. The fast rate of aisles degradation was observed in the newly built Mvog Betsi market. Rapid degradation is as a result of erosion since the market is located on a slope, compounded by the absence of roof gutters, the poor disposition of surface drains and the relatively light nature of tar used to pave the aisles.

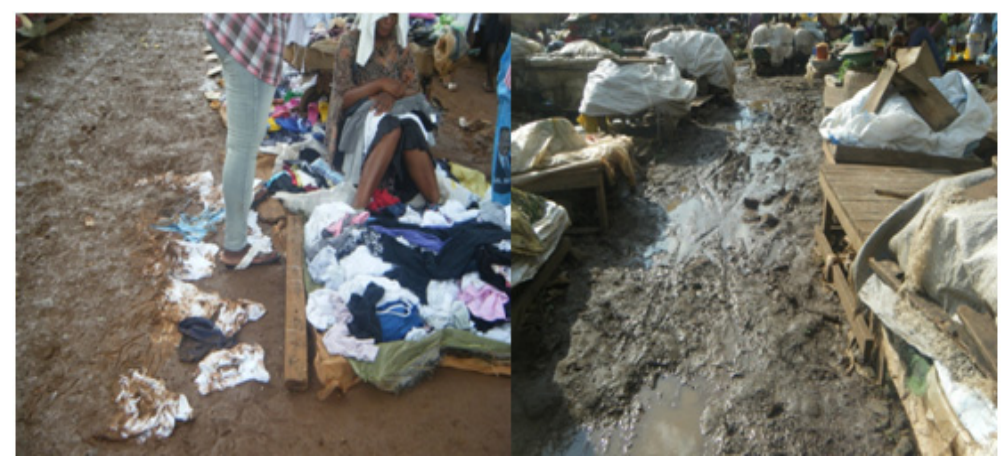

Figure 5(a). Muddy aisles in the Essos market

Tracy-white (1995) posited that in order to ensure the free circulation of customers and wheel barrows, aisles width ought to be in the range of 3.5-6 m. The minimum width allows a group of three people walking together to pass one person standing by a shop, or for two people walking to pass two other people. The $6 \mathrm{~m}$ width aisles would allow for seating, other uses and is particularly good for the main thoroughfare of markets. This is a luxury in Yaounde markets where the average width of aisles is $1 \mathrm{~m}$ and minor aisles are even less than $1 \mathrm{~m}$. This is as a result of vendor encroachment as shown in Figure 5(b).

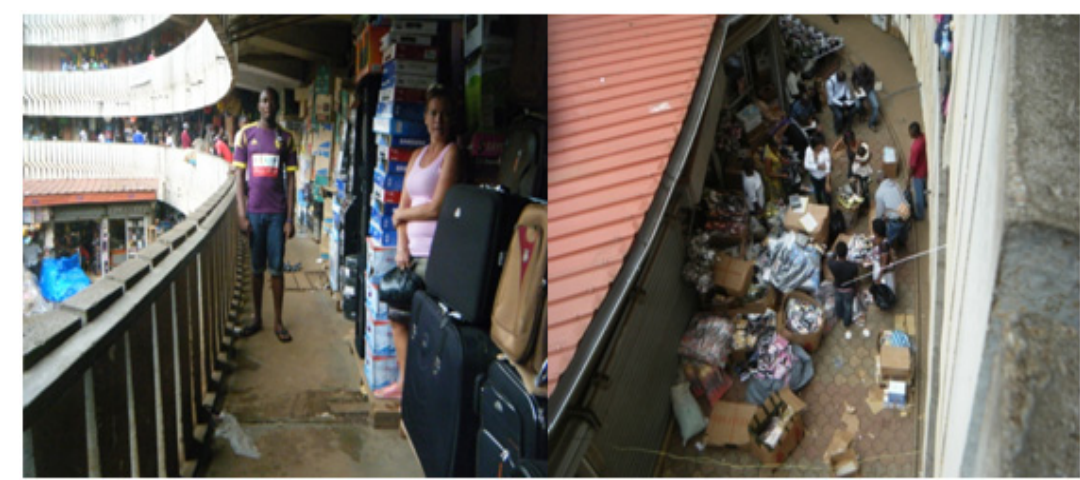

Figure 5(b). Invaded aisles at the Yaounde Central Market

Poor economic performance and rapid population growth in cities have forced people into petty trading in markets. In order to accommodate the increasing numbers of traders, aisles widths have been compromised.

\subsubsection{Roads and Sidewalks}

For traffic to be fluid around a market, the size of the road should be $7 \mathrm{~m}$ for a one-way road and $12 \mathrm{~m}$ for two-way roads (Tracy-White, 1995). For sidewalks, $2.5 \mathrm{~m}$ was set as the minimum and $5.2 \mathrm{~m}$ if road side stalls are to be accommodated (Tracy-White, 1995). In the case of the Mokolo market, shops are located on an average of $5 \mathrm{~m}$ from the road, while the sidewalks measure $2 \mathrm{~m}$ in width. However, due to the marketability of this market, petty traders have occupied sidewalks and aisles, making circulation difficult.

Only $30.8 \%$ of markets have an internal road system. However, vendors have entirely colonised the internal road system which could serve as a way through which goods are offloaded. This is the case of the Mvog Mbi, Mokolo and Elig-Edzoa markets. 


\subsubsection{Car Parks and Offloading Zones}

It was noticed that $61.5 \%$ of markets do not have a parking lot specifically carved out for the market. In the Mokolo and Mvog Betsi, car parks have been turned into commercial spaces. In the Essos market, the parking bay has been transformed into a taxi station for commuters from the Mimboman neighbourhood. This has encouraged car parking on narrow roads around markets in turn hampering fluid circulation. Moreover, the absence of an offloading zone in Yaounde markets, permits heavy trucks to offload their cargo at any point and time in the market. The presence of heavy trucks on internal market thoroughfares inhibit customer circulation and limits the exposure of buyers to the full range of goods sold.

\subsubsection{Non-Functional Nature of Stand Pipes}

Many markets lack potable water. These are the cases of the Mfoundi and Ekounou markets. According to the Director of the Mfoundi market, the pump in this market was closed because of the abusive use of this facility especially for laundering. Consequently, traders in these markets have to buy potable water.

\subsubsection{Official Clinic}

The location of clinics in markets increases access to health services. It was noticed that $61 \%$ of markets do not have an official clinic. Thus, traders resort to the use of drugs of doubtful quality sold by mobile medicine vendors. This is a hazardous practice.

\subsubsection{Electrical Supply and Street Lighting}

Electrical connections in Yaounde markets are often called 'spider webs' because they are highly interwoven and illegal. This practice has been identified as the main source of electrical short-circuits leading to devastating fire outbreaks in these markets. The presence of 'spider webs' is lesser in the Central market which is relatively well planned in terms of the built-up area than in the Mfoundi and Mvog Betsi markets. The Mfoundi market and other under developed markets like those of Nsam, Mendong, Mvog Mbi, and Essos have not been official electrified. Consequently, electrical power is informally tapped from adjacent neighbourhoods in disrespect of safety norms.

Findings show that only the Essos and Central markets have circuit breakers installed at traders' shops as safeguards against fire outbreaks. Given that $53.7 \%$ of fire outbreaks in the city's markets from 2008 to 2011 occurred during non-trading hours $(06: 00 \mathrm{pm}-06: 00 \mathrm{am})$ circuit breakers are necessary installations. Between 2008 and July 2011, the fire fighting brigade made 54 interventions in various markets in Yaounde; 25.9\% in 2008 and $42.6 \%$ of in 2009 . Over $59 \%$ of traders still perceive fire as the greatest security threat in the markets.

A secure power supply system is vital for ensuring adequate security in markets. It helps night watchmen to efficiently do their job and protect traders who reach the market with goods from villages during dark hours. Five markets (Mfoundi, Mvog Betsi, Essos and Central) are partially lit by lamp posts, while the rest do not have security lamps.

\subsubsection{Hydrant Points and Fire Extinguishers}

The location of hydrant points in markets is very important because the fire fighting brigade can easily fill their tanks at the vicinity instead of going back to their base. This saves time and increases efficiency. It was observed that only the Central market has a non-functional hydrant point. Furthermore, traders do not have fire extinguishers to fight outbreaks before fire fighters come. This has often led to wide spread fire devastations in markets.

\subsubsection{Security Concerns}

The need for adequate levels of security in Yaounde's markets is unquestionable. It was found out that the Mendong, Mvog Ada, Etoudi, and Ekounou markets did not have a police post. Its absence has helped to deepen the level of crime in these markets. In Mvog Ada for instance, marijuana (cannabis sativa), an illegal drug is often smoked behind the market. Another infrastructural requirement which is necessary to ensure security as well as law and order is a fence. Only the Mfoundi, Mokolo and the Central market are fenced. In unfenced markets, thieves have easy access all the time. A fence can also help to deter traders from encroaching onto the road network, even though this has not been successful in the Mfoundi market.

\subsubsection{Suitability of Trade}

Despite the low level of infrastructural development in markets, $71 \%$ of traders are satisfied with the sales spaces they occupy, taking into consideration the fact that the marketable spaces are in very high demand. About $29 \%$ are not satisfied because of the miniature stalls which make trade inconvenient. Dissatisfaction was also fuelled 
by the unprofitable nature of trade in the Mvog Betsi market. The satisfaction with sales space occupied is not a true reflection of the sustainability of the practice of commodity trade in Yaounde. This is because some traders located close to the road are satisfied with the spaces they occupy, despite their precarious physical conditions. According to a survey conducted at the Mfoundi market by the former Market Director who is now the Director of the Central market; road side vending is more profitable than core market trading. The profitable nature of trade in and around the entrance of the market and the fear of displacement to relatively unprofitable sites also influences traders' decisions to assert that they are satisfied with sales spaces occupied. Secondly, women who are most exposed to precarious trading conditions think trading conditions have improved over the years. Furthermore, no matter how disorganised the market is, how poor sales spaces are, a sizeable number of traders remain satisfied, so far as free trade is not hampered. Generally, satisfaction with trading spaces can actually serve as an indicator that the current wave of rehabilitation in markets is yielding fruits.

\section{Discussion}

Uzuegbunam (2012) and Adekunle (2012) studied the Nkwo-Ozuluogu market in Oraifite, Anambra State, and that of Oje and Oja'ba in Ibadan all in Nigeria respectively, and pointed to the fact that these markets are characterised by dilapidated structures, encroachment on roads, inadequate parking facilities, lack of adequate water supply, electricity and other public utilities, inefficient refuse disposal, weak municipal services, community facilities and incessant fire outbreaks. Poor or fragmented infrastructural development is also a feature of Yaounde markets. In the Oje market, only one toilet facility serves the entire market which is obviously not adequate. The fact that the toilet facilities are inadequate and far from some people have made some traders to excrete in a bucket or plastic wrapping inside their shop before disposing of it into the available dust bins, open drains and stream when they are returning home in the night (Adekunle, 2012). This is very similar to the practice in the Essos market that has only one toilet block with 4 compartments. In this market, the toilet is about $120 \mathrm{~m}$ away from some traders and also largely insufficient. As a result, traders have created illegal toilets around the market.

Gantner (2009) posited that because the physical structure of the Kariakoo market in Dar es Salaam has been outsized by the ever-expanding metropolis, most of the market activity is now mobile, thus extending the physical manifestation of the market beyond its perimeter walls. In Yaounde, traders have carved out spaces along the market fringes that respond to their needs. In some cases, traders whose stalls are removed from the most accessible and customer convergence points hire mobile vendors to hand-carry their stock towards the customers thereby increasing congestion and limiting customer circulation in the market.

According to Gombay (1994), as cities in the developing world continue to grow and urban poverty increases, more people rely on urban markets as a means of survival. Inadequate employment opportunities have forced people into petty trading in and around markets in Yaounde. Consequently, their infrastructural carrying capacities have been surpassed. As city populations continue to increase rapidly, it is unreasonable to assume that the provision of infrastructure would multiply in proportion (Rowena, 1969). This is the case of the Mokolo market in which the site constructed for petty traders can accommodate only 300 of them, whereas this group numbers over 2000 .

At the end of the civil war in Somalia, hundreds of small-scale vendors altered the urban form around the Hargeisa Central market in Mogadishu, while two big market structures in the same area remained unused (UN-HABITAT, 2010). Because of the unprofitable nature of trade in underused markets, formal sector traders joined the small scale traders. As a result, income and tax revenues for municipal authorities dropped drastically, traffic was chaotic, while meat and vegetables were sold in unhygienic conditions. This is reminiscent of the Mvog Mbi and Mvog Betsi markets in which the traders have deserted a part of the market because of its non-marketability. Tracy-white (1995) thinks that the typical range of infrastructure that might be needed for the upgrading of urban markets includes: internal access roads and parking, paving and sales pitches, surface water drainage, tube wells/hand pumps, latrines and, if appropriate, the provision of a market supervisor's office. Traders can also contribute to the embellishment of the market by, improving building spaces which they rent on a long-term basis or by providing temporary shade structures.

\section{Conclusion and Recommendations}

This study reveals the fact that the poor planning in the provisioning of economic and social infrastructure in Yaounde market has affected their efficient functioning. This has also contributed to urban inefficiency as a result of market fringe trading and resultant traffic congestion. Furthermore, inadequate infrastructure in markets has contributed to sanitation concerns as well as environmental degradation.

The government of Cameroon needs to review its regional development policy so as to limit the number of 
rural-urban migrants, many of who can only survive in the city through petty trading.

As regards waste management, a platform to ease waste dumping should be constructed by the City Council as illustrated in Figure 6(a) for a single bin and Figure 6(b) for double bins. This could help to prevent the dumping of waste brought by truck or wheel barrow out of the bins because of ill adapted structures.

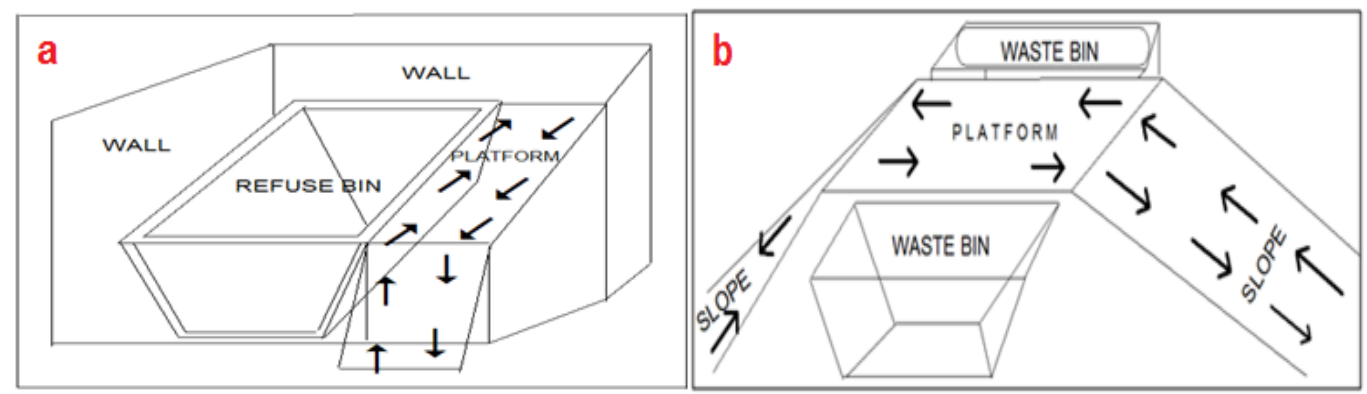

Figure 6. (a) proposed waste disposal platform for a single bin, (b) Proposed waste disposal platform for double bins

The Electricity Development Corporation together with the City Council must institute order in power supply in the markets by ensuring secured connections to the electrical grid.

There is need for council authorities to use incombustible building materials like burnt-brick and asbestos roofing sheets which are less costly and environmentally friendly so as to avoid devastating fires in markets built of wood.

To make the Mvog Betsi market more functional, the City Council should reorganize the market and transfer wholesale activities to this location.

In other to improve their attractiveness, market development plans should include the following:

- Taxi pick up and drop off zones delimited and implemented around markets

- Commercial motor parks spaces demarcated from the parking space meant for clients and traders.

- Sidewalks around markets should measure $2.5 \mathrm{~m}$ and separated from the road by a short gate, with gateways put at specific points as done in Arab countries (Shibam in Southern Yemen and Rabat in Morocco) and Yaounde especially in Central market. In the case where roadside shops are to be accommodated, pavements should be $5.2 \mathrm{~m}$ wide.

- In the markets to be constructed, aisles width should be in the range of 3.5-6 m, wide enough to ease pedestrian circulation and small delivery trolleys.

- Latrines and urinals should be located an optimum distance of $50 \mathrm{~m}$ and a maximum distance of $100 \mathrm{~m}$ from users.

- Water pump should be located at a maximum distance of $100 \mathrm{~m}$ from the furthest user (50 m preferred). Meat the fish stalls should have running water for continuous cleaning.

- Refuse bins should be located at a maximum distance of 50m from users (25 m preferred) and the main refuse bins located out of the market in a reserved environment.

- Lamp post placed at an interval of $15 \mathrm{~m}-25 \mathrm{~m}$.

- Markets should be fenced.

- Pitch markings of $1 \mathrm{~m}$ should be delimited for each trader.

- Internal road systems should measure a width of $7 \mathrm{~m}$.

- Two way roads around markets should $12 \mathrm{~m}$ wide.

- Functional hydrant points should be installed in all markets

- Internal road systems should be constructed in markets with an associated loading and offloading zone

- Each market should have a dispensary and a police post

- Livestock markets should have a modern abattoir (this is necessary in the Mvog Ada market) 


\section{References}

Adekunle, F. B. (2012). Management of traditonal markets in Ibadan, Nigeria: A focus on Oja'ba and Oje markets. $\quad$ Retrieved August 14, 2013, from http://www.regionalstudies.org/uploads/balogun_femi_adekunle.pdf

Adewole, A. T. (2009). Waste management towards sustainable development in Nigeria: A case study of Lagos state. Int. NGO J, 4(4), 173-179.

Gantner, G. (2009). The urban market: social and spatial configuration in the inner city. African Perspectives.

Gombay, C. (1994). Market place politics in Kampala and Quinto. Urban Age: Politics and the City, 2(2).

Parry, J. A., Ganaie, S. A., Nengroo, Z. A., \& Bhat, M. S. (2012). Spatial Analysis on the provision of Urban Amenities and their Deficiencies-A Case Study of Srinagar City, Jammu and Kashmir, India. Research on Humanities \& Social Sciences, 2(6).

Rowena, M. L. (1969). The supply response of retail trading services to urban population growth in Ghana. In M. Claude (Ed.), The development of indigenous trade and markets in West Africa. Studies Presented and Discussed at the Tenth International African Seminar at Fourah Bay College, Freetown, December, 1969. London: Oxford University Press.

Tracy-White, J. D. (1995). Retail market planning guide. FAO Agricultural Service Bulletin. Rome: Fiat Panis.

Uzuegbunam, F. O. (2012). Sustainable Development for Traditional Market-Places in South-Eastern Nigeria: A Case Study of Nkwo-Ozuluogu Market in Oraifite,Anambra State. Nigeria Journal of Environmental Management and Safety, 3(1), 139-158.

\section{Copyrights}

Copyright for this article is retained by the author(s), with first publication rights granted to the journal.

This is an open-access article distributed under the terms and conditions of the Creative Commons Attribution license (http://creativecommons.org/licenses/by/3.0/). 